\title{
Ekokardiografi Mode-Brightness pada Ular Sanca
}

\section{(BRIGHTNESS-MODE EKOCARDIOGRAPHY ON THE PHYTON SNAKES)}

\section{Mokhamad Fakhrul Ulum ${ }^{1 *}$, Nurul Aeni Ayu Lestari ${ }^{2}$, Amira Putri Pertiwi², Muhammad Piter Kombo ${ }^{3}$, Ligaya Ita Tumbelaka ${ }^{1}$}

\author{
${ }^{1}$ Divisi Reproduksi dan Kebidanan, Departemen Klinik, Reporoduksi, dan Patologi, Fakultas \\ Kedokteran Hewan, Institut Pertanian Bogor, Jalan Agatis, Kampus IPB Dramaga Bogor \\ 16680 Jawa Barat; ${ }^{2}$ Program Pendidikan Profesi Dokter Hewan, Fakultas Kedokteran Hewan, \\ Institut Pertanian Bogor, Jalan Agatis, Kampus IPB Dramaga Bogor 16680 Jawa Barat; \\ ${ }^{3}$ Taman Reptil, Taman Mini Indonesia Indah, Jalan Raya Taman Mini, DKI Jakarta. \\ *Email: ulum@ipb.ac.id
}

\begin{abstract}
ABSTRAK
Ekokardiografi merupakan salah satu teknik diagnosis kesehatan organ jantung dengan memanfaatkan gelombang suara berfrekuensi tinggi yang bersifat non-invasif, aman, cepat, dan mudah dilakukan. Penelitian ini bertujuan untuk mengamati struktur, ukuran, dan posisi organ jantung pada tiga spesies sanca, yaitu sanca batik, sanca bodo, dan sanca bola. Organ jantung dicitrakan menggunakan ultrasonografi mode-brightness dengan transduser jenis linear berfrekuensi $10 \mathrm{MHz}$ dan menggunakan media air sebagai pengganti gel ultrasound. Ular dikekang dan ditangani secara fisik, tanpa menggunakan sedasi ataupun obat bius selama pencitraan berlangsung. Posisi organ jantung diukur berdasarkan nomor sisik ventral, sedangkan ukuran organ jantung diukur berdasarkan jumlah sisik ventral. Hasil pencitraan menunjukkan bahwa posisi organ jantung berada pada nomor sisik ventral ke-55 sampai ke-77, sedangkan ukuran organ jantung berkisar 12-13 sisik ventral. Posisi jantung sanca batik cenderung lebih anterior dibandingkan sanca bodo dan sanca bola. Citra ultrasonografi pada standar pandang longitudinal memperlihatkan bagian jantung berupa sinus venosus, atrium kanan, atrium kiri, cavum arteriosum, cavum venosum, cavum pulmonale, arteri pulmonum, dan aorta. Sedangkan pada standar pandang transversal memperlihatkan bagian dari cavum venosum, cavum pulmonale, cavum arteriosum, dan aorta. Otot organ jantung memiliki ekogenisitas yang berwarna abuabu (hipoekoik) dengan ruang jantung berisi darah yang tampak berwarna hitam (anekoik). Sedangkan jaringan jantung yang lebih liat tampak berwarna putih (hiperekoik).
\end{abstract}

Kata kunci: ekokardiografi; jantung; sanca; sisik ventral; ultrasonografi

\begin{abstract}
Echocardiography is one of the health diagnostic techniques of cardiac organ by utilizing highfrequency sound waves that are non-invasive, safe, fast, and easy to do. This study aims to observe the structure, position, and size of cardiac organ in the three species of phyton (sanca), namely sanca batik, sanca bodo, and sanca bola. The cardiac organs were imaged using ultrasonography of brightness mode with a $10 \mathrm{MHz}$ linear type transducer and using a water medium as an ultrasound gel. Snakes were handled and restrained physically, without the use of sedation or anesthesia. The position of the cardiac organ is measured by the number of the ventral scales, while the size of the cardiac organ is measured by the amount of ventral scales. The results indicate that the position of the cardiac organ is at the number 55-77 ventral scales, while the size of the cardiac organ ranges from 12-13 ventral scales. The position of the cardiac organ on sanca batik tends to be more anterior than sanca bodo and sanca bola. Ultrasonographics of the longitudinal standard of view showed the cardiac parts of the sinus venosus, right atrium, left atrium, cavum arteriosum, cavum venosum, cavum pulmonale, pulmonary artery, and aorta. Whereas in transversal standard of view showed the parts of cavum venosum, cavum pulmonale, cavum arteriosum, and aorta. The muscle of the cardiac organs has a gray (hypoechoic) echogenicity with a blood vessel that appears to be black (anechoic). While the more clayey's cardiac tissue appeared as white color (hyperechoic).
\end{abstract}

Keywords: echocardiography; cardiac; phyton; ventral scales; ultrasonography 


\section{PENDAHULUAN}

Jantung merupakan organ vital pada semua makhluk hidup. Organ jantung memiliki beberapa fungsi, antara lain untuk mengangkut nutrisi dan oksigen ke seluruh tubuh, serta sisa metabolisme (Hall, 2011). Umumnya jantung mamalia memiliki empat ruang yang terpisah. Berbeda dengan mamalia, ular yang termasuk ke dalam kelas reptilia hanya memiliki tiga ruang jantung, yang terdiri atas septum atrium lengkap dan kanal interventrikular (Funk, 1996). Berbagai kasus penyakit yang dapat menganggu sistem kardiovaskular ular, yaitu endokarditis, congestive heart failure (Jacobson et al., 1991), kardiomiopati (Frye, 1991), neoplasma (Frye, 1994; Hruban et al., 1992), dan trombus kardia (Konell et al., 2015). Laporan tentang penyakit kardiovaskular pada reptil saat ini masih jarang ditemui, umumnya kasus didiagnosa dari temuan postmortem (Snyder et al., 1999). Teknik diagnosis yang cepat, aman dan tepat pada hewan hidup saat ini sangat diperlukan guna mendukung manajemen kesehatan yang lebih baik.

Ekokardiografi merupakan salah satu teknik diagnosis kesehatan organ jantung dengan memanfaatkan gelombang suara berfrekuensi tinggi (Coucelo et al., 1996). Teknik ini bersifat non-invasif, aman, cepat, dan mudah dilakukan (Gammal, 1993; Stahlschmidt et al., 2011; Gnudi et al., 2009). Ekokardiografi dapat diketahui struktur anatomi, fungsi, maupun diagnosis beberapa penyakit pada ular (Schilliger $e t$ al., 2005). Meskipun citra organ paru-paru dan jantung secara mikro-CT pada sanca bola telah dilakukan oleh van Soldt et al., (2015), akan tetapi publikasi tentang penggunaan teknologi ekokardiografi pada ular di Indonesia saat ini masih belum dilaporkan. Penelitian ini melaporkan pencitraan ekokardiografi, ukuran dan posisi organ jantung berdasarkan acuan sisik ventral pada tiga spesies sanca, yaitu sanca batik, sanca bodo, dan sanca bola secara transkutan. Hasil penelitian ini diharapkan dapat menjadi acuan bagi para dokter hewan dalam mendiagnosis kelainan maupun penyakit jantung pada ular hidup.

\section{METODE PENELITIAN}

\section{Hewan Coba}

Ular sanca yang digunakan sebagai objek penelitian adalah sanca batik (Malayopython reticulatus), sanca bodo (Python bivittatus), dan sanca bola (Python regius). Ular sanca diperoleh dari penghobi dan Taman Reptil Taman Mini Indonesia Indah.

\section{Pencitraan Ekokardiografi}

Ekokardiografi mode-brightness dilakukan menggunakan perangkat ultrasonografi (SonoDop®， S-3X, PT Karindo Alkestron, Indonesia) dengan jenis tranduser linear berfrekuensi $10 \mathrm{MHz}$. Standar pandang yang digunakan adalah longitudinal dan transversal terhadap sumbu tubuh ular sanca. Air digunakan sebagai pengganti gel ultrasound untuk memudahkan dalam proses pengambilan gambar karena ular sanca cenderung terus bergerak dan sulit ditangani. Ular ditangani dan dikekang dengan baik tanpa menggunakan obat bius atau sedasi selama pencitraan berlangsung. Bagian tubuh ular yang dicitrakan direndam dalam air didalam bak air untuk menghasilkan pencitraan yang baik. Pencitraan organ jantung dilakukan pada bagian sepertiga depan tubuh ular dari arah ventral. Dokumentasi dilakukan menggunakan kamera digital telepon genggam (Lenovo ${ }^{\circledR}$, A7000 kamera 8 MP, PT Lenovo Indonesia).

\section{Penentuan Posisi dan Ukuran Jantung}

Ukuran dan posisi organ jantung ditentukan dengan menandai sisik ventral dimana organ jantung ditemukan pada pencitraan ultrasonografi. Penghitungan sisik ventral dilakukan sebagai orientasi dalam mencari organ dihitung mulai dari sisik ventral pertama yang ada di leher tepat belakang kepala di bagian ventral dari tubuh hingga sisik ventral terakhir pada bagian depan lubang kloaka. 


\section{Analisis Data}

Data yang diperoleh dianalisa dan disajikan secara deskriptif-naratif.

\section{HASIL DAN PEMBAHASAN}

Posisi organ jantung mudah untuk ditemukan secara ultrasonografi dan berada di sepertiga depan dari total panjang tubuh ular (Gambar 1). Citra ultrasonografi pada standar pandang longitudinal memperlihatkan jantung memiliki bentuk yang cenderung oval dengan bagian-
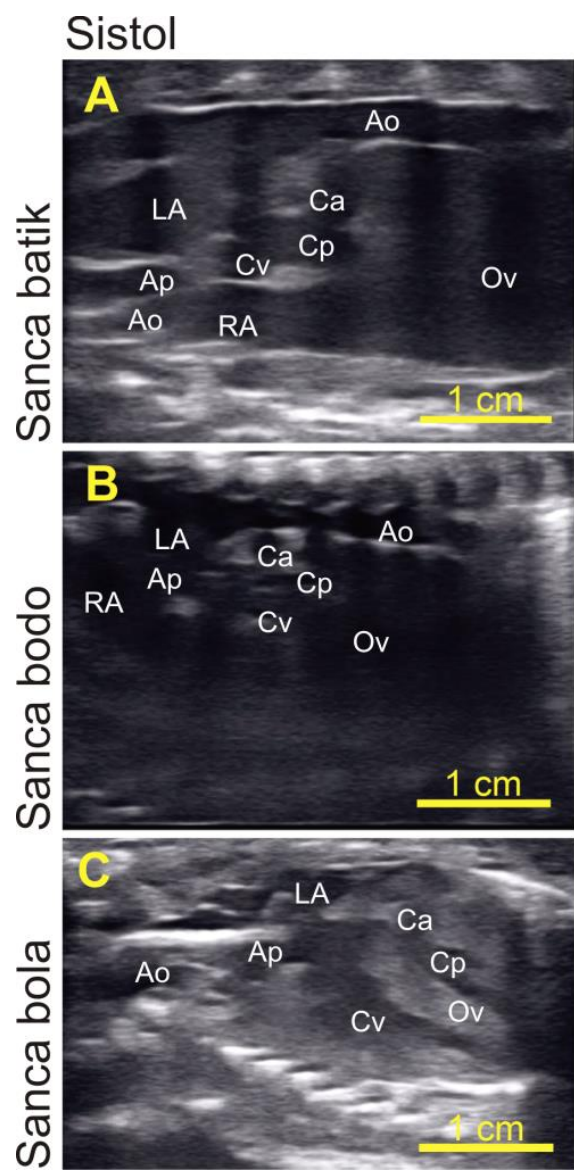

Gambar 1 Sonogram jantung saat sistol dan diastole pada (A) sanca batik (Malayopython reticulatus) posisi pandang longitudinal, (B) sanca bodo (Python bivittatus) posisi oblik, dan (C) sanca bola (Python regius) posisi transversal.

Atrium kanan dan kiri yang memiliki dinding tipis sehingga sulit untuk dilihat. Begitu pula dengan sinus venosus sulit untuk dicitrakan, hal ini disebabkan karena memiliki ekogenisitas yang tampak hampir anekoik. Cavum arteriosum, cavum venosum, dan cavum pulmonale mudah untuk ditemukan, hal ini dikarenakan ketiga

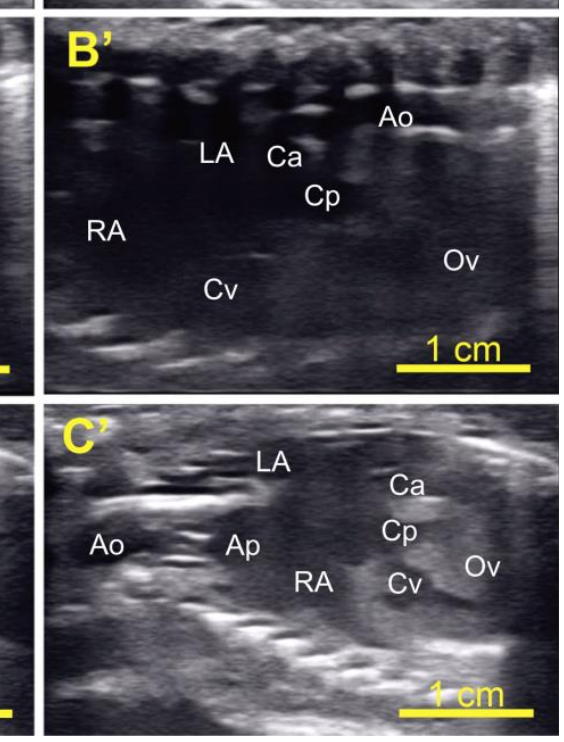

bagian, antara lain atrium kanan (RA), atrium kiri (LA), cavum arteriosum (Ca), cavum venosum $(\mathrm{Cv})$, cavum pulmonale $(\mathrm{Cp})$, arteri pulmonum (Ap) dan aorta (Ao). Pengamatan pada standar pandang transversal memperlihatkan jantung memiliki bentuk membulat dengan bagianbagian, yaitu cavum venosum, cavum pulmonale, cavum arteriosum, dan aorta. Otot ventrikel (Ov) tampak tebal dan tampil sebagai citra hipoekoik. Ruangan dan saluran pada jantung yang berisi darah tampak anekoik.

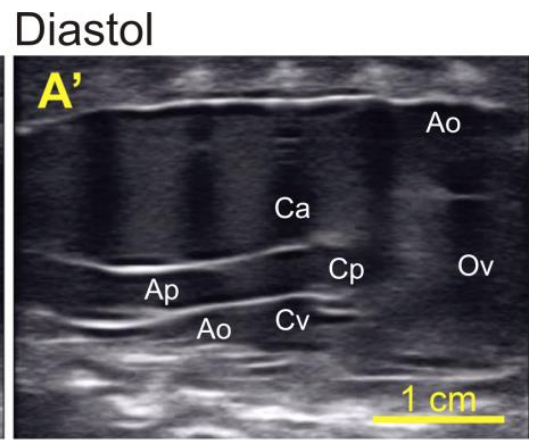

cavum memiliki dinding yang tebal dibandingkan atrium. Cavum arteriosum berlokasi di bawah atrium kanan, cavum venosum yang berbentuk seperti lengkungan berada di bawah atrium kiri, sedangkan cavum pulmonale berlokasi di antara cavum arteriosum dan cavum venosum. Arteri pulmonum berhimpitan 
dengan aorta, memiliki bentuk seperti pipa dengan dinding yang tampak hiperekoik.

Tabel 1 menunjukkan posisi dan ukuran organ jantung berdasarkan selang, nomor dan jumlah sisik ventral dari ketiga sanca. Posisi organ jantung berdasarkan nomor sisik pada ketiga sanca terdapat perbedaan. Posisi organ jantung ketiga Sanca berhimpitan pada selang sisik ventral nomor 55 sampai dengan nomor 77. Nomor acuan sisik ventral menunjukkan bahwa posisi organ jantung ular Sanca batik dan Sanca bola memiliki nomor sisik yang berdekatan. Sedangkan nomor sisik pada Sanca bodo lebih rendah dari Sanca batik dan Sanca bola. Ukuran organ jantung berdasarkan jumlah sisik ventral pada ketiga sanca cenderung tidak berbeda. Ukuran jantung ketiga sanca memiliki ukuran sepanjang 12-13 sisik ventral.

Tabel 1 Posisi dan Ukuran Organ Jantung Ular Sanca Berdasarkan Selang, Nomor dan Jumlah Sisik Ventral

\begin{tabular}{cccc}
\hline \multirow{2}{*}{ Jenis sanca } & \multicolumn{2}{c}{ Posisi } & Ukuran \\
\cline { 2 - 4 } & Selang $(\mathbf{S V})$ & Nomor $(\mathbf{S V})$ & Jumlah $(\mathbf{S V})$ \\
\hline Batik & $62-74$ & 68 & 12 \\
$\begin{array}{c}\text { (Malayopython reticulatus) } \\
\text { Bodo }\end{array}$ & $55-67$ & 61 & 12 \\
$\begin{array}{c}\text { (Python bivittatus) } \\
\text { Bola } \\
\text { (Python regius) }\end{array}$ & $64-77$ & 70 & 13 \\
\hline
\end{tabular}

Penelitian ini telah berhasil melakukan pencitraan ekokardiografi pada ular sanca (Gambar 1). Posisi dan ukuran organ jantung pada ular sanca dengan mudah ditemukan berdasarkan nomor sisik ventral (Tabel 1). Secara anatomi, ular tidak memiliki diafragma pemisah antara rongga perut dengan rongga dada sedemikian sehingga organ jantung didalam rongga tubuh dapat bergerak dengan mudah ke cranial maupun ke kaudal (Isaza et al., 1993; Schilliger et al., 2005; Murray, 1996). Kondisi ini dimaksudkan agar makanan yang berukuran besar dapat dengan mudah melewati esofagus menuju lambung (Farrel et al., 1998).

Sanca batik termasuk hewan arboreal atau sebagian hidupnya di atas pohon, sedangkan sanca bodo dan sanca bola merupakan hewan terestrial, atau sebagian hidupnya di atas tanah (Vosjoli, 2003). Perbedaan habitat tersebut ternyata memengaruhi posisi organ jantung (Tabel 1). Anderson dan Secor (2015) menyatakan bahwa habitat berpengaruh terhadap posisi organ, dimana jantung Sanca batik cenderung lebih anterior dibandingkan sanca bodo dan sanca bola (Gartner et al.,
2010). Hewan arboreal dapat meminimalisasi kerja jantung untuk memompa darah menuju otak karena jarak jantung dan kepala cenderung lebih dekat (Badeer, 1998). Ukuran organ jantung ketiga spesies tidak menunjukkan banyak perbedaan dimana organ tubuh akan bertambah besar sesuai dengan pertambahan ukuran sisik ventral (Tabel 1). Menurut Lindell et al., (1993) ukuran sisik ventral memiliki korelasi positif dengan pertumbuhan tubuh pada ular.

Organ jantung pada ular memiliki bentuk memanjang atau oval dan diselubungi oleh kantung perikardium (Farrel et al., 1998). Pencitraan ekokardiografi pada ular sanca menunjukkan hal yang serupa (Gambar 1). Otot organ jantung yang merupakan jaringan lunak memiliki ekogenisitas yang berwarna abu-abu atau hipoekoik, sedangkan ruang jantung yang berisi darah tampak berwarna hitam atau anekoik (Noviana et al., 2012). Lokasi organ jantung berdekatan dengan kelenjar tiroid di bagian depan dari paru-paru dan hati (Schilliger et al., 1994). Lokasi organ hati berdasarkan sisik ventral berada di posisi 
persinggungan sisik ventral 72-102 (Lestari et al., 2017). Jantung ular memiliki ventrikel tunggal dengan bentuk kerucut terbalik dan tepi yang membulat (Schilliger et al., 2005), sepasang atrium dimana atrium kanan lebih berkembang dari atrium kiri, serta sinus venosus yang terletak di dorsal atrium kanan (Snyder et al., 1999).

Sistem sirkulasi dan anatomi organ jantung reptilia berbeda dengan mamalia. Sebagaimana diuraikan oleh Snyder (1999), bahwa darah yang kembali ke jantung dari seluruh tubuh masuk melalui sinus venosus, dan menuju ke atrium kanan melalui katup bikuspidalis sinus venosus. Kemudian darah melalui katup atrioventrikular kanan menuju cavum venosum. Saat diastol, cavum venosum menjadi jalur darah yang bergerak menuju cavum pulmonale dan saat sistol, darah bergerak menuju cavum pulmonale dan kemudian ke arteri pulmonalis (Gambar 1). Darah yang sudah diperkaya oksigen di paru-paru akan bergerak melalui vena pulmonalis memasuki atrium kiri dan menuju ke cavum arteriosum. Selama sistol, darah dari cavum arteriosum melewati vertikal septum, lalu melalui kanal interventrikular menuju cavum venosum. Kemudian darah keluar menuju lengkung aorta kanan dan kiri dari cavum venosum (Snyder, 1999). Darah yang mengalir melalui kedua lengkung aorta merupakan campuran antara darah yang mengandung kaya oksigen dan darah yang sangat sedikit mengandung oksigen. Namun, kontraksi vertikal septum saat diastol dan horizontal septum saat sistol menyebabkan terjadinya pemisahan sempurna antara sirkulasi pulmoner dan sistemik (Schilliger et al., 2005).

\section{SIMPULAN}

Ekokardiografi pada sanca mudah dilakukan secara transkutan dengan pengekangan secara fisik. Citra organ jantung ketiga spesies dapat ditemukan pada posisi sisik ventral antara nomor 5577. Bagian-bagian organ jantung yang berisi cairan tampak anekoik, sedangkan jaringan lunak seperti otot tampak hipoekoik dan jaringan yang lebih keras tampak hiperekoik. Ukuran jantung pada ketiga spesies adalah berkisar 12-13 sisik ventral.

\section{SARAN}

Perlu dilakukan penelitian lanjutan berupa kajian Doppler ekokardiografi berikut citra 3D dan 4D organ jantung pada ular sanca.

\section{UCAPAN TERIMAKASIH}

Terima kasih disampaikan kepada PT Karindo Alkesteron yang telah menyediakan perangkat ultrasonografi dan Taman Reptil Taman Mini Indonesia Indah serta para penghobi Sanca yang telah mengijinkan dilakukan pencitraan dalam penelitian ini.

\section{DAFTAR PUSTAKA}

Anderson G, Secor S. 2015. Ontogenetic shifts and spatial associations in organ positions for snake. Zoology. 118: 403412.

Badeer HS. 1998. Anatomical position of heart in snakes with vertical orientation: a new hypothesis. Comp. Biochem. Physiol. Part A: Mol. Integ. Physiol. 119(1): 403-405.

Coucelo J, Coucelo J, Azevedo J. 1996. Ultrasonography characterization of heart morphology and blood flow of lower vertebrates. J. Exp. Zool. 275: 7382.

Farrell AP, Gamperl AK, Francis ETB. 1998. Comparative aspects of heart morphology. In Gans C, Gaunt AS: Biology of the Reptilia vol. 19, Morphology G. Visceral organs. Society for the Study of Amphibians and Reptiles. New York (USA): Ithaca. Pp. 375-424.

Frye FL. 1991. Biomedical and Surgical Aspects of Captive Reptile Husbandry 2nd ed. Melbourne: FL Krieger Publishing. Pp. 481.

Frye FL. 1994. Diagnosis and surgical treatment of reptilian neoplasms with a 
compilation of cases 1966-1993. In Vivo. 8(5): 885-892.

Funk RS. 1996. Biology - snakes. In Mader DR (ed): Reptile Medicine and Surgery. Philadelphia: WB Saunders Co. Pp. 3946.

Gammal E, Auer T, Hoffmann K, Matthes U, Altmeyer P, Ermert H. 1993. Highfrequency ultrasound: a non-invasive method for use in dermatology. In Noninvasive Methods in Dermatology, Frosch P, Kligman A. Heidelberg: Springer Verlag. Pp. 104.

Gartner GEA, Hicks JW, Manzani PR, Andrade DV, Abe AS, Wang T, Secor SM, Garland T. 2010. Phylogeny, ecology, and heart position in snakes. Physiol. Biochem. Zool. 83: 43-54.

Gnudi G, Volta A, Ianni F, Bonazzi M, Manfredi S, Bertoni G. 2009. Use of ultrasonography and contrast radiography for snake gender determination. Vet. Radiol. Ultrasound. 50(3): 309-311.

Hall J. 2011. Guyton and Hall textbook of medical physiology $12^{\text {th }}$ Ed. Philadelphia (US): Saunders/Elsevier.

Hruban Z, Vardiman E, Meehan T. 1992. Hematopoietic neoplasms in zoo animals. J. Comp. Pathol. 106: 15-24.

Isaza R, Ackerman N, Jacobson ER. 1993. Ultrasound imaging of the coelomic structures in the Boa constrictor (Boa constrictor). Ve. Radiol. Ultrasound. 34(6): 445-450.

Jacobson ER, Homer B, Adams W. 1991. Endocarditis and congestive heart failure in a burmese python (Python molurus bivittatus). J. Zoo Wildlife Med. 22: 245-248.

Konell A, Sanson BC, Giannico AT, Werner J, Ferreira FM, Froes TR, Lange RR. 2015. Cardiac thrombus in a burmese python (Python molurus bivittatus). The Herpetological Bul. 131: 13-16.

Lestari NAA,Pertiwi AP, Kombo MP, Tumbelaka L, Ulum MF. 2017.
Pencitraan ultrasonografi organ hepatobiliari pada ular sanca. ARSHI Vet. Letters. 1(2): 29-30.

Lindell L, Forsman A, Merila J. 1993. Variation in number of ventral scales in snakes: effects of body size, growth rate and survival in the adder (Vipera berus). J. Zool. 230: 101-115.

Murray MJ. 1996. Cardiology and circulation. In Mader DR (ed): Reptile Medicine and Surgery. Philadelphia: WB Saunders Co. Pp. 95-104.

Noviana D, Aliambar S, Ulum M, Siswandi R. 2012. Diagnosis Ultrasonografi pada Hewan Kecil. Bogor (ID): IPB Press. Pp. 8.

Schildger BJ, Casares M, Kramer M, Spörle $\mathrm{H}$, Gerwing M, Rübel A, Tenhu $\mathrm{H}$, Göbel T. 1994. Technique of ultrasonography in lizards, snakes and chelonians. Seminars in Avian and Exotic Pet. Med. 3: 147-155.

Schilliger L, Chetboul V, Tessier D. 2005. Standardizing two-dimentional echocardiographic examination in snakes. Exotic DVM. 7(3): 63.

Snyder PS, Shaw NG, Heard DJ. 1999. Two-dimensional echocardiographic anatomy of the snake heart (Python molurus bivittatus). Vet. Radiol. Ultrasound. 40: 66-72.

Stahlschmidt Z, Brashears J, DeNardo D. 2011. The use of ultrasonography to assess reproductive investment and output in pythons. Biol. J. Linnean Soc. 103: 772-778.

van Soldt BJ, Metscher BD, Poelmann RE, Vervust B, Vonk FJ, Muller GB, Richardson MK. 2015. Heterochrony and early left-right asymmetry in the development of the cardiorespiratory system of snakes. PLOS ONE. 10(1): e116416.

Vosjoli P. 2003. The Ball Python Manual. California (USA): Advanced Vivarium Systems. Pp. 7. 